\title{
Investigasi Numerik Efek Kekasaran Permukaan (Adhesi) pada Kontak Gesek antara Karet Sbr-25 dengan Rigid Indenter
}

\author{
Budi Setiyana \\ Departemen Teknik Mesin, Fakultas Teknik, Universitas Diponegoro \\ Jl. Prof. H. Sudarto, SH Tembalang - Semarang Kotak Pos 1269 \\ *E-mail: bsetiyana@yahoo.com
}

\begin{abstract}
In a wide range of existing material properties, when receiving external loads, such as force, pressure, or strain will show different responses, depending on the nature of the material. Rubber or rubber compound (elastomer) is often modelled as a hyperelastic material. The theory of hyperelastic model has been developed by some researchers such as Yeoh theory which is generally used for filled rubber with carbon black as in Styrene Butadiene Rubber (SBR). A numerical investigation is proposed in this study to describe the frictional contact between a spherical rigid indenter and filled SBR with 25\% carbon black (SBR-25). This study was developed by Finite Element Analysis (FEA) by using ABAQUS 6.14-5 software. This frictional contact is observed to obtain a coefficient of friction which generally consists of two components namely the adhesion component (due to surface roughness) and hysteresis components (due to deformation along friction). The contact simulation between rigid indenter and surface of hyperelastic material are made with variation of coefficient of adhesion friction, that is $0,0.15,0.5$ and 1.0. The results obtained in the form of reaction horizontal force, hysteresis friction coefficient and total coefficient of friction with respect to sliding displacement of indenter. Based on the simulation results, the high surface roughness causes the high total coefficient of friction however, fluctuative values are emerged. These cases indicate that the stick-slip phenomena occur of the contact between indenter and rubber surface.
\end{abstract}

Keywords: adhesion; hyperelastic; coefficient of friction; SBR-25

\section{Abstrak}

Dalam berbagai macam perlakuan material yang ada, perlakuan material ketika menerima beban luar, baik beban berupa gaya, tekanan, ataupun regangan akan menunjukkan respon yang berbedabeda, tergantung pada sifat material tersebut. Material karet atau karet kompon (elastomer) sering dimodelkan sebagai material hyperelastic. Teori tentang model material hyperelastic telah dikembangkan oleh beberapa peneliti seperti teori Yeoh yang umumnya dipakai untuk karet kompon (elastomer) yang diisi dengan carbon black seperti pada Styrene Butadiene Rubber (SBR). Tulisan ini menyajikan investigasi numerik pada kontak gesek antara sebuah rigid spherical indenter dengan material SBR yang diisi 25\% berat carbon black (SBR-25). Penelitian dilakukan berbasis Metoda Elemen Hingga dengan menggunakan software ABAQUS 6.14-5. Kontak gesek ini akan menghasilkan besar koefisien gesek yang secara umum terdiri dari dua komponen yaitu komponen adhesi (akibat kekasaran permukaan) dan komponen hysteresis (akibat deformasi). Kontak gesek antara indenter dengan permukaan material SBR-25 dibuat dengan variasi koefisien gesek adhesi sebesar 0, 0.15, 0.5 dan 1 yang nilainya diberikan sebagai data masukan. Hasil yang didapat berupa hubungan gaya reaksi, koefisien gesek hysterisis dan koefisien gesek total terhadap perpindahan geser indenter. Berdasarkan hasil simulasi ditunjukkan bahwa semakin besar kekasaran permukaan, akan menyebabkan munculnya nilai koefisien gesek total yang besar pula tetapi besarnya fluktuatif. Kejadian ini menunjukkan adanya fonemena kontak stick-slip antara indenter dengan permukaan karet.

Kata kunci: adhesi; hyperelastic; koefisien gesek; SBR-25

\section{Pendahuluan}

Sebuah material ketika menerima beban luar, baik beban berupa gaya, tekanan, ataupun regangan akan menunjukkan respon yang berbeda-beda antara material satu dengan yang lainnya. Penyebabnya, tidak lain adalah perbedaan sifat tiap material itu sendiri. Sifat material dalam merespon adanya beban luar dapat berupa sifat elastic, elastic-plastic, plastic, hyperelastic, viscoelastic, maupun viscoplastic.Untuk mengetahui sifat suatu material, perlu dilakukan suatu pengujian pada material tersebut. Sebagai contoh uji tekan dan uji gesek pada suatu material karet yang 
sering dimodelkan sebagai material hyperelastic yang dilakukan untuk mengetahui fenomena yang terjadi. Dalam analisis kontak gesek secara umum, material karet bersifat lebih lunak dari material penggoresnya (indenter).

Secara umum koefisien gesek pada kontak gesek pada material hyperelastic terdiri dari dua komponen, yaitu komponen adhesi yang disebabkan oleh kekasaran permukaan dan komponen hysteresis yang disebabkan oleh deformasi permukaan material. Kekasaran permukaan ini sudah biasa dikaitkan dengan koefisien gesek pada material logam atau material kaku lainnya. Tetapi pada material karet, sifat yang mudah berubah bentuk atau terdeformasi akan memberikan kontribusi pada koefisien gesek total. Fenomena ini memunculkan koefisien gesek akibat deformasi atau hysteresis. Yang umumnya terjadi adalah fenomena stick-slip baik dalam kontak gesek maupun kontak abrasi [1-2].

Penelitian ini dilakukan terhadap kasus kontak antara material elastomer jenis Styrene-butadiene Rubber (SBR-25) dengan rigid ball indenter, dimana permukaan elastomer masih halus dan belum terabrasi sama sekali. Nilai konstanta material hyperelastic ditentukan berdasarkan hasil uji tarik oleh Liang, dengan menggunakan model Yeoh untuk SBR25. Analisa uji indentasi gesek menggunakan metode elemen hingga dengan bantuan software Abaqus 6.14-5 yang merupakan salah satu software metode elemen hingga yang populer digunakan [3]. Selain itu software Abaqus 6.14-5 menyediakan fasilitas analisa non-linier untuk mekanika kontak.

Jenis material hyperelastic yang digunakan mempunyai strain energy function model Yeoh untuk SBR-25, dengan nilai konstanta $\mathrm{C}_{10}=0,337 \mathrm{MPa}, \mathrm{C}_{20}=-0,0053 \mathrm{MPa}, \mathrm{C}_{30}=0,0005 \mathrm{MPa}, \mathrm{D}=0,062(\mathrm{Mpa})^{-1}$ dan nilai densitasnya sebesar $\rho=0,00112 \mathrm{~g} / \mathrm{mm}^{3}$ [4]. Variasi kekasaran permukaan kontak diwakili oleh koefisien gesek adhesi yang divariasi sebesar 0,0.15,0,5 dan 1.0. Hasil yang didapat dari penelitian ini yaitu berupa gaya reaksi, koefisien gesek hysteresis, dan koefisien gesek total terhadap perpindahan atau pergeseran indenter.

\section{Material dan Metode Penelitian}

Gambaran kasus dari penelitian ini dimodelkan dalam bentuk 2 dimensi (plane strain) dengan geometri yang dijelaskan pada Gambar 1. Sisi kanan dan kiri elastomer ditumpu pada arah horizontal dan dapat bergerak bebas arah vertikal, sedangkan bagian bawah elastomer ditumpu mati. Penyelesaian kasus ini dilakukan menggunakan metode elemen hingga dengan bantuan software Abaqus 6.14-5. Indentasi dilakukan dengan memberi kedalaman tertentu, kemudian memberikan perpindahan indenter pada arah horizontal [5-6]. Variasi nilai koefisien gesek diberikan mulai dari nilai 0, 0.15, 0.5 dan $1 \mathrm{~mm}$. Hasil yang didapat berupa gaya reaksi dan koefisien gesek yang terjadi selama kontak gesek. Fokus hasil yang dianalisis adalah saat terjadinya kontak gesek (friction).

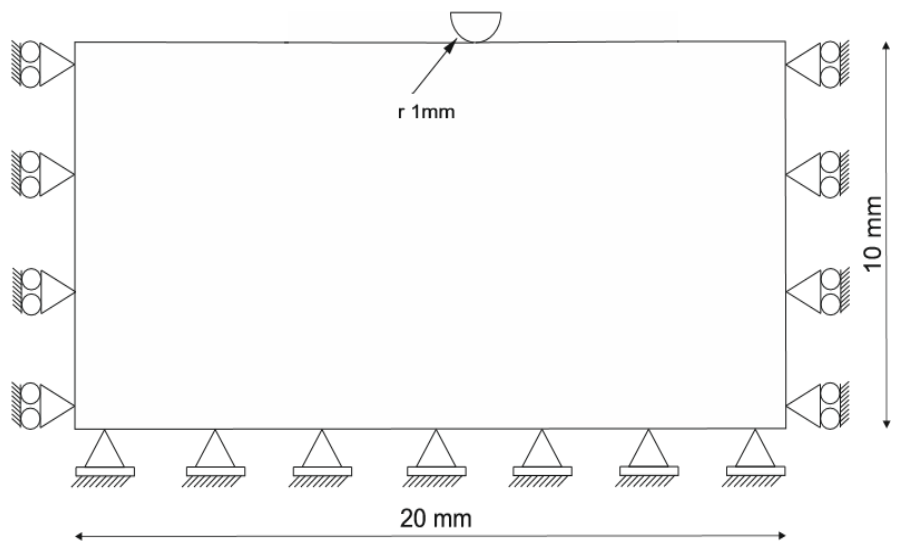

(a)

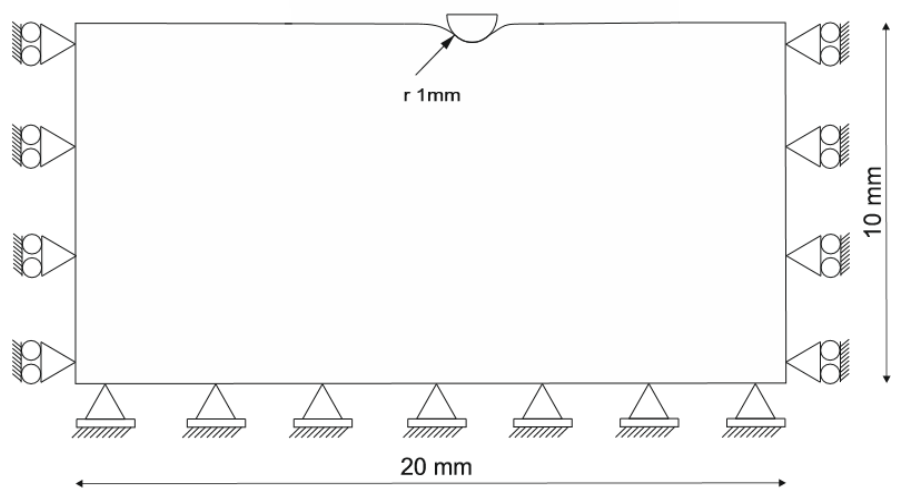

(b) 


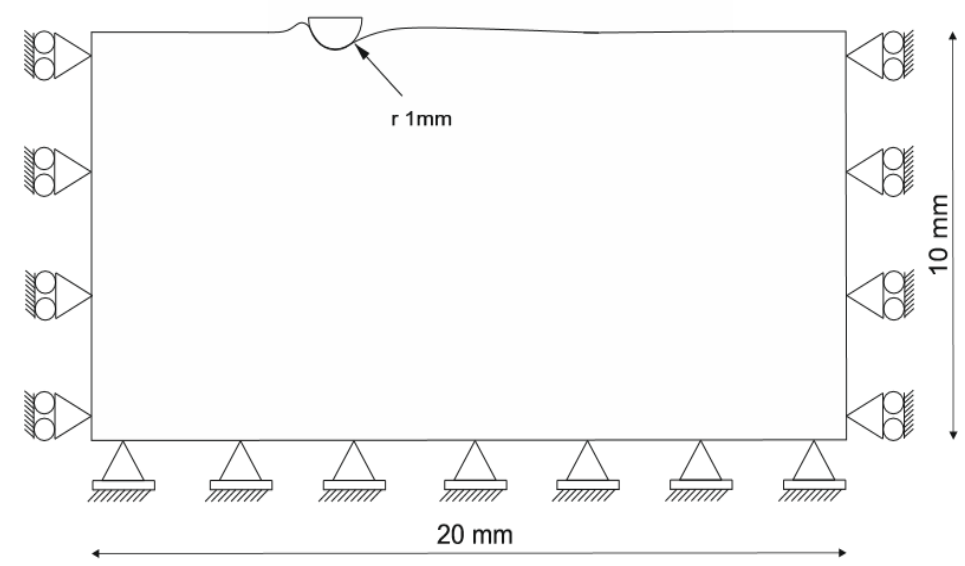

(c)

Gambar 1. Pemodelan kontak gesek antara indenter dengan radius $\mathrm{r}=1.0 \mathrm{~mm}$ dan permukaan elastomer (a) Kondisi awal (b) Kondisi setelah penekanan (c) Kondisi akhir setelah indenter bergeser kekiri.

Gambar 1 merupakan skema pemodelan dari elastomers dimana elastomers tersebut diibaratkan memiliki permukaan yang halus dan rata. Panjang spesimen elastomers $20 \mathrm{~mm}$, lebar dari elastomers $10 \mathrm{~mm}$ dan radius indenter disimbolkan dengan r. Pemodelan uji tekan dan geser dimulai dengan menentukan parameter dari model yang meliputi parameter material, kondisi batas dan dimensi dari elastomers dan indenter. Sebelum melakukan simulasi pada Abaqus 6.14-5 diperlukan beberapa part yang akan digunakan untuk membuat pemodelan yang selanjutnya akan disimulasikan. Pembuatan part sendiri bisa dengan mengimport dari software CAD seperti Solidworks, Catia, Auto Cad ataupun yang lainya, tetapi jika pemodelan part-nya masih sederhana bisa membuat part sendiri dengan menggunakan Abaqus.

Langkah selanjutnya adalah pemberian properties pada kedua part diatas. Untuk part elastomers diberikan properties berupa masa jenis dan sifat hyperelastic yang diisi oleh koefisien Yeoh untuk SBR-25. Properties dari elastomers dapat dilihat pada tabel 1 dibawah ini. Sedang untuk indenter properties yang diberikan berupa masa jenis, sifat plastic dan elastic.

Tabel 1. Properti material yang digunakan dalam pemodelan

\begin{tabular}{llllll}
\hline Materials & $C_{10} / \mathrm{MPa}$ & $C_{20} / \mathrm{MPa}$ & $C_{30} / \mathrm{MPa}$ & $D_{\mathrm{Com}} /(\mathrm{MPa})^{-1}$ & $\rho / \mathrm{g} / \mathrm{mm}^{3}$ \\
\hline SBR-25 & 0.337 & -0.0053 & 0.0005 & 0.062 & 0.00112 \\
\hline
\end{tabular}

Setelah pemberian properties pada kedua part, langkah selanjutnya adalah pemberian step tekan dan geser serta memberi beberapa input diantaranya kedalaman indentasi $1 \mathrm{~mm}$, koefisien gesek 1, sliding horizontal sejauh 8 mm. Untuk part indenter dibuat rigid pada saat pemberian boundary condition. Langkah berikutnya adalah pemberian mesh pada kedua part seperti pada gambar 2 berikut ini.

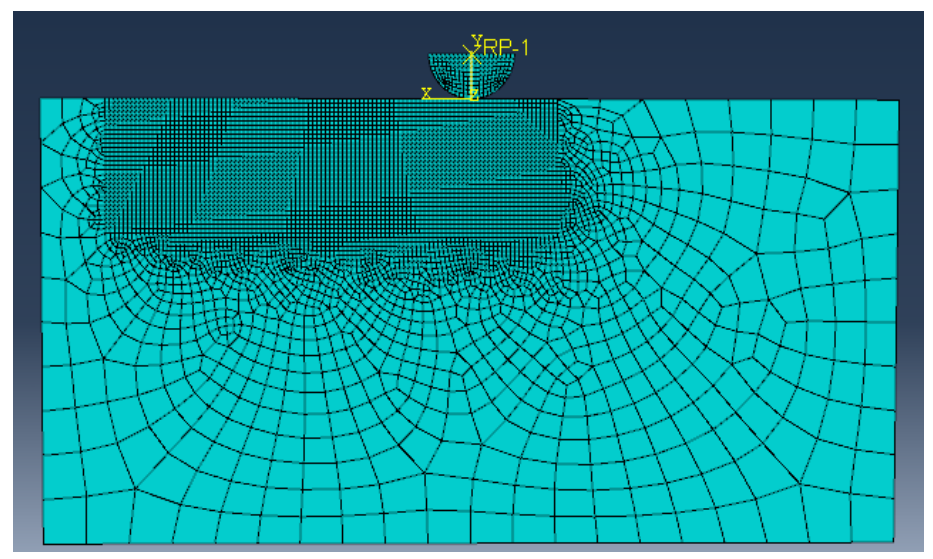

Gambar 2. Meshing pada karet (elastomer) dan indenter

Langkah yang terakhir adalah sovling problem yaitu mensimulasikan kontak gesek antara elastomers dan indenter dengan masuk ke module job dan menunggu hasil simulasi sampai hasil nya dapat ditampilkan dan dianalisis. 


\section{Hasil dan Pembahasan}

Dari semua pemodelan yang telah dibuat ada beberapa output yang didapat diantaranya yaitu : gaya reaksi horizontal, koefisien gesek hysterisis dan koefisien gesek total. Hasil plotting gaya reaksi horizontal terhadap perpindahan indenter dengan variasi koefisien gesek pada material SBR-25 dan kedalaman indentasi 1.0 mm terlihat bahwa grafik tersebut juga memiliki kontur yang fluktuatif. Pada koefisien gesek adhesi 0 sampai 1 nilai gaya reaksi meningkat sampai jarak perpindahan $8 \mathrm{~mm}$. Dan pada koefisien gesek adhesi 1.0 menghasilkan grafik yang bersifat fluktuatif. Nilai gaya pada koefisien gesek adhesi 1.0 lebih tinggi dibandingkan dengan koefisien gesek adhesi lainnya. Jadi semakin tinggi nilai koefisien gesek adhesi maka semakin tinggi pula nilai gaya reaksi yang dihasilkan seperti terlihat pada Gambar 3.

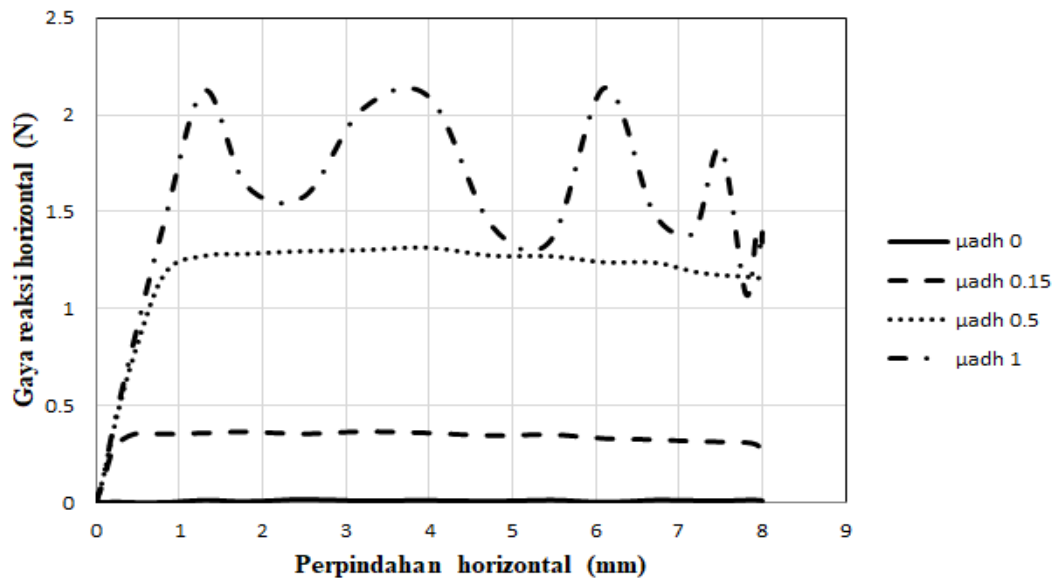

Gambar 3. Gaya reaksi horizontal terhadap perpindahan indenter dengan variasi koefisien gesek adhesi $\mu_{\text {adh }}$ dan kedalaman indentasi $1,0 \mathrm{~mm}$

Pada Gambar 4 menunjukkan perubahan besarnya nilai koefisien gesek hysterisis yang terjadi seiring dengan semakin besarnya perpindahan indenter pada material SBR-25. Pemodelan ini dilakukan pada kedalaman indentasi sebesar $1.0 \mathrm{~mm}$ dan variasi koefisien gesek adhesi 0, 0.15, 0.5 dan 1. Dari grafik terlihat bahwa semakin tinggi pada koefisien gesek adhesi $\mu_{\mathrm{adh}}$ semakin tinggi juga koefisien gesek hysteresisnya, tetapi akan menjadi fluktuatif pada $\mu_{\mathrm{adh}}$ $=1.0$.

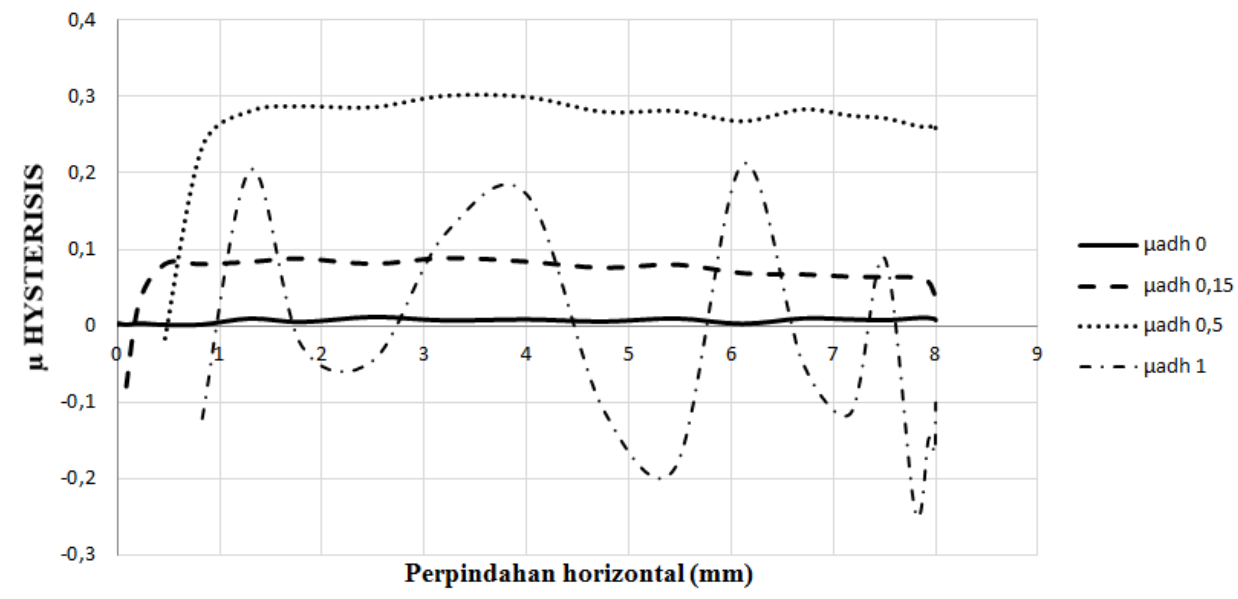

Gambar 4. Koefisien gesek hysterisis terhadap perpindahan indenter untuk kedalaman indentasi 1.0 mm dan variasi koefisien gesek adhesi

Gambar 5 menunjukkan perubahan besarnya nilai koefisien gesek total terhadap perpindahan (pergeseran) indenter dengan elastomer. Pemodelan ini dilakukan pada kedalaman indentasi sebesar $1.0 \mathrm{~mm}$ dan variasi koefisien gesek adhesi. Terlihat semakin tinggi koefisien gesek adhesi, koefisien gesek total semakin meningkat tetapi pada $\mu_{\mathrm{adh}}=1.0$ nilainya terlihat fluktuatif. Pemodelan dengan $\mu_{a d h}=1.0$ menghasilkan nilai koefisien gesek total yang tinggi dibandingkan dengan pemodelan lainnya. Semakin besar koefisien gesek adhesi maka nilai koefisien gesek total juga semakin tinggi. 


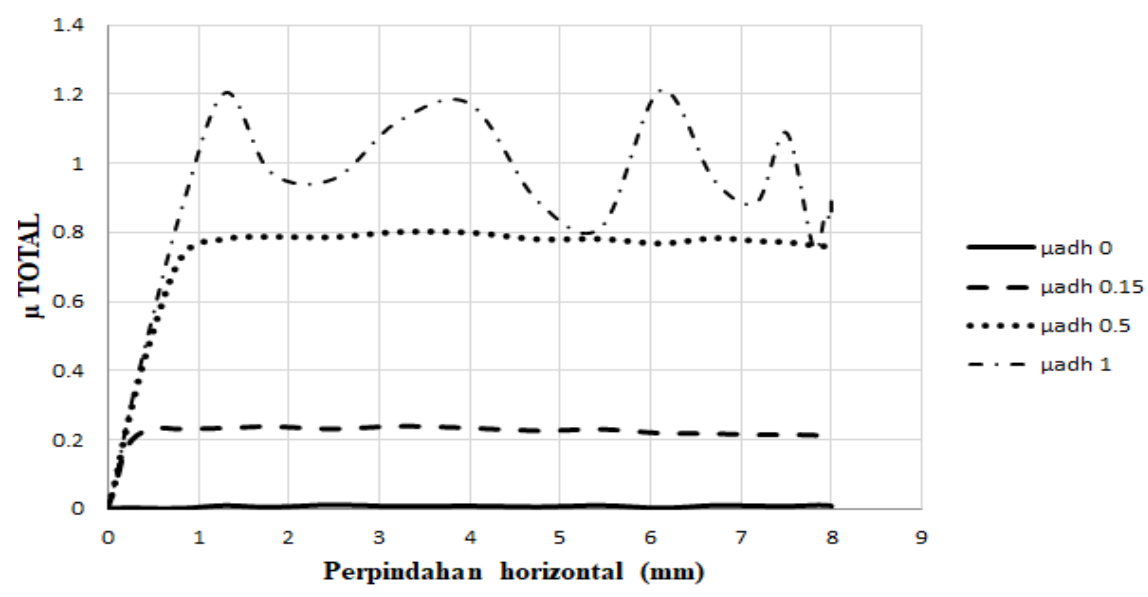

Gambar 5. Koefisien gesek total terhadap perpindahan indenter pada kedalaman indentasi $1.0 \mathrm{~mm}$ dan variasi koefisien gesek adhesi

Secara umum gaya reaksi, koefisien gesek hysterisis dan koefisien gesek total yang fluktuatif akibat adhesi atau kekasaran permukaan yang tinggi menyebabkan adanya fenomena stick-slip yang merupakan fenomena yang umum terjadi pada kontak gesek dengan elastomer. Gaya normal atau indentasi yang dalam akan menyebabkan stick dimana ujung indenter dengan permukaan kontak bergerak bersama. Jika gaya gesek sudah melampaui gaya gesek statik maka terjadilah gaya gesek kinetik atau slip. Dan fenomena ini akan terjadi secara periodik dan berulang-ulang.

\section{Kesimpulan}

Kajian mengenai kontak gesek hyperelastic menggunakan metode elemen hingga pada kondisi smooth surface, dimana permukaan elastomers masih halus dan belum mengalami abrasi ini telah menunjukkan karakteristik material hyperelastic. Dari hasil simulasi variasi koefisien gesek adhesi menghasilkan beberapa output diantaranya gaya reaksi horisontal, koefisien gesek hysteresis dan koefisien gesek total. Indentasi menggunakan rigid spherical indenter yang bergeser dengan kedalaman ternetu. Dari serangkaian hasil simulasi tersebut didapatkan beberapa kesimpulan, yaitu:

1. Semakin besar kekasaran permukaan atau koefisien gesek adhesinya maka semakin besar pula gaya reaksi horisontal, koefisien gesek hysterisis dan koefisien gesek total yang dihasilkan. Pada koefisien gesek adhesi sebesar 1.0 dan kedalaman $1.0 \mathrm{~mm}$ didapat :

- Gaya reaksi horisontal tertinggi yaitu sebesar $2.41 \mathrm{~N}$

- Koefisien gesek total tertinggi sebesar $1.21 \mathrm{~N}$

- Koefisien gesek hysteresis tertinggi sebesar $0.30 \mathrm{~N}$

2. Pada permukaan yang kasar, gaya reaksi, koefisien gesek hysteresis dan koefisien gesek total yang fluktuatif menunjukkan adanya fenomena stick-slip yang merupakan fenomena yang umum terjadi pada kontak gesek dengan elastomer.

\section{DAFTAR PUSTAKA}

[1] Setiyana B., Ismail R., Jamari J., Schipper D., 2016, "Stick-slip behaviour of a viscoelastic flat sliding along a rigid indenter," Journal of Tribology Online 11, 4 (2016) 512-518.

[2] Fukahori Y.,Yamazaki H., 1994, "Mechanism of rubber abrasion,” Wear 178(1)109-116.

[3] ABAQUS 6.11, 2011, "Standard User's Manual,” Dassault Systems Simulia Corp., USA.

[4] Liang, H., 2007, “Investigating the Mechanism of Elastomer Abrasion,” Ph.D. thesis, University of London. London.

[5] Setiyana B., Ismail R., Jamari J., Schipper D., 2017, “A Numerical Investigation of Mechanical Behavior of unfilled styrene-butadiene rubber by static straight blade indentation,” Journal of Mechanical Engineering, SI 1 (1) 45-53.

[6] Setiyana B., Ismail R., Jamari J., Schipper D., 2017, "A Numerical Investigation of the Friction Contact of an Unfilled Styrene Butadiene Rubber by a Blade Sliding Indentation,” International Conference of Computation on Science and Engineering, Bandung Institute of Technology, Bandung. 